\title{
Quantitative Detection of Aloin and Related Compounds Present in Herbal Products and Aloe vera Plant Extract Using HPLC Method
}

\author{
Kaliyaperumal Logaranjan ${ }^{1}$, Thiyagarajan Devasena ${ }^{2}$, Kannaiyan Pandian ${ }^{\text {* }}$ \\ ${ }^{1}$ Department of Inorganic Chemistry, University of Madras, Guindy Campus, Chennai, India \\ ${ }^{2}$ Centre for Nanoscience and Nanotechnology, Anna University, Chennai, India \\ Email: *jeevapandian@yahoo.co.uk
}

Received January 4, 2013; revised February 4, 2013; accepted March 1, 2013

Copyright (C) 2013 Kaliyaperumal Logaranjan et al. This is an open access article distributed under the Creative Commons Attribution License, which permits unrestricted use, distribution, and reproduction in any medium, provided the original work is properly cited.

\begin{abstract}
We have developed a novel methodology for the determination of Aloins A and B in Aloe vera plant extract and commercial Aloe vera product formulations using HPLC method. The result shows good sensitivity and accuracy which can be utilized for the scientific validation of bioactive compounds present in the commercial formulations.
\end{abstract}

Keywords: Aloe vera; Aloin; HPLC

\section{Introduction}

Aloe vera L. is a perennial plant with turgid green leaves joined at the stem in a rosette pattern [1]. It has gained high importance for its diverse therapeutic properties. The plant contains major quantities of water and seventy five different ingredients including vitamins, minerals, enzymes, sugars, anthraquinones or phenolic compounds, lignin, tannic acids, polysaccharide, glycoprotein, saponins, sterols, amino acids and salicylic acid [1]. The structures of some bioactive compounds present in Aloe vera L. are shown in Figure 1. Aloe vera provides nutrition, shows anti-inflammatory action and has a wide range of antimicrobial activity. It can be used not only in the medicine for the treatment of various diseases, but also as an ointment and cosmetics [2]. Aloe vera products have long been used in health foods for medical and preservative purposes. Aloe contains two major active materials: one is the aloe polysaccharides presenting in aloe filet; the other is anthraquinone derivatives existing in the leaves of different aloe plants [3]. The major constituents have multiple pharmacological actions including laxative, anti-bacterial, anti-inflammation, hemostatic, and antispasmodic [4-9]. These constituents are isolated by various extraction methods such as pressurized hot water extraction [10], ultrasonic and microwave extraction [11], supercritical $\mathrm{CO}_{2}$ extraction [12], and pressurized liquid extraction [13]. Fernand et al. [14] extracted

${ }^{*}$ Corresponding author. the active components from C. alata L. using solid-phase extraction coupled with HPLC analysis. Later Gong et al. [15] used the ionic liquid separation of the Aloe vera constituent determined by HPLC method. It is complicated to determine the amount of each compound in an herb because of the existence of many active components in it. It is important to establish a simple, rapid and accurate quantitative method for the quality control of commercial formulated products. Here we demonstrated the determination of the Aloe vera product in real samples and commercial cosmetics products such as lotion and syrups in order to measure the exact concentration of the active components. Also the proposed method can be utilized for the scientific validation of the commercial products. This method provides an easy, economical, and efficient hydrolysis condition for the validation of commercial products.

\section{Experimental Section}

\subsection{Chemicals}

Aloins are used for the control of retention times and HPLC grade methanol and Acetonitrile were purchased from Sigma-Aldrich (St. Louis, USA). AR grade ethanol, sulfuric acid and chloroform were purchased from Sigma-Aldrich. Ultra pure water $\left(18.2 \mathrm{M} \Omega \cdot \mathrm{cm}^{-1}\right)$ was obtained by means of a MilliQ apparatus by Millipore, USA. Stock solutions of the analyte $(1 \mathrm{mg} / \mathrm{mL})$ were 


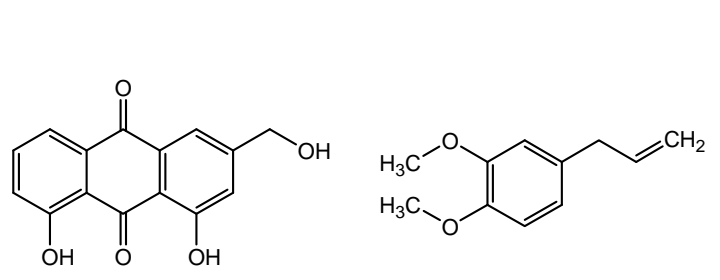

Aloe emodin (AEM)

(a)

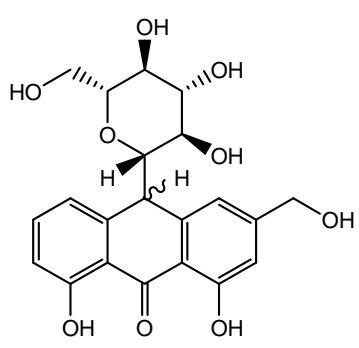

Aloins (A and B)

(c)

Figure 1. Bioactive compounds present in Aloe vera extract (a) Aloe emodine, (b) Eugenol methyl ester, (c) Aloins A \& B.

prepared by dissolving suitable amounts of each pure substance in methanol and were stable for at least two months when stored at $-20^{\circ} \mathrm{C}$ (as assessed by HPLC assays). Standard solutions were prepared daily by diluting stock solutions with the mobile phase and directly injected into the HPLC system.

\subsection{Methods}

A High Performance Liquid Chromatography (HPLC) equipped with gradient elution capability, Ultraviolet spectrophotometer (UV, model 2487) and photodiode array (PDA, model 2996) as detector and an auto sampler (Waters Alliance system, model 2965). Data handling system used Waters Empower-2. A stainless steel column of length $250-\mathrm{mm}$, internal diameter $4.6-\mathrm{mm}$ filled with waters proprietary phase chemically bonded to porous modified silica particles of $5 \mu$ diameter which is used Waters X-Terra RP-8 $(250 \times 4.6 \mathrm{~mm}), 5 \mu$ column. The mobile phase consisted in the ratio of water (78\%) and acetonitrile $(22 \%)$. The detection wavelength was $220 \mathrm{~nm}$ and the flow rate was $1.0 \mathrm{~mL} / \mathrm{min}$. Each injection volume was $20 \mu \mathrm{L}$. The column temperature maintained at ambient condition.

\subsection{Preparation of Crude Plant Materials}

The extract was prepared by the method reported in the literature [16]. Aloe peel powder was soaked in $60 \%$ ethanol solution for $24 \mathrm{hrs}$. The solution and residue were isolated by a centrifuge ( $800 \mathrm{~B}$, Changsha) at a rolling speed of $4000 \mathrm{rpm}$. A reddish brown colloid containing aloe extractive was obtained. Sulphuric acid and chloroform were added into the extractive and refluxed to remove the chloroform extractive. This procedure was carried out in triplicates. After the evaporation of the chloroform, a yellowish-brown colloid was obtained as crude extract. Stock solution was prepared by dissolving in methanol.

\section{Method Validation}

Determination of total AQs content is measured at maxi- mum absorbance wavelength $(220 \mathrm{~nm})$ in Figure 2. Triplicate runs were carried out for each partitioning experiment for accuracy (Table 1). The method was calibrated by analyzing five standard samples with known amount of 1,8-dihydroxyanthraquinone in the range 0.0066 $0.0350 \mu \mathrm{g} \cdot \mathrm{mL}^{-1}$. The linear regression equationy $=27.7 \mathrm{x}$ +0.0057 was constructed by plotting the absorbance (A) as a function of the pure AQs concentration (c) with a correlation coefficient of $\mathrm{r}=0.9996$ and the relative standard deviation (RSD) of $2.4 \%$. Limit of detection (LOD) is the lowest analyte concentration that could be detectable above the noise level of the system, was measured generally three times the standard deviations of the blank $(\mathrm{S} / \mathrm{N}>3.3)$. The LOD was defined as the formula,

$$
\mathrm{DL}=\frac{3.3 \sigma}{\mathrm{S}}
$$

where DL, $\sigma$ and $\mathrm{S}$ are limit of detection, the standard deviation of the response and the slope of the calibration curve respectively.

The linear regressions and correlative coefficients were determined based on the calibration curves. The real concentrations were derived from the standard curves and used to calculate the standard deviation (SD) and coefficient of variation (CV), which were used as indexes for the precision and relative error for accuracy, respectively. The LOD determination of total AQs concentration was $0.0038 \mu \mathrm{g} \cdot \mathrm{mL}^{-1}$. The HPLC data for the reference standards and samples are shown in Figure 3. This study attempted to establish an HPLC method for simultaneous determination of the aloin and aloe-emodin contents in aloe-extracts and aloe-containing lotion and syrups. HPLC chromatograms of aloin and aloe-emodin in aloe-containing products and standards are shown in Figure 3. For simultaneous analysis of two ingredients with different polarities, an isocratic elution analysis system was used. These three compounds were well resolved within $30 \mathrm{~min}$. The retention time of Aloins A and $\mathrm{B}$ was observed at 9.4 and $10.9 \mathrm{~min}$ respectively. While recording Aloe vera plant extract, these Aloins A and B values are slightly red shifted and appeared at retention 


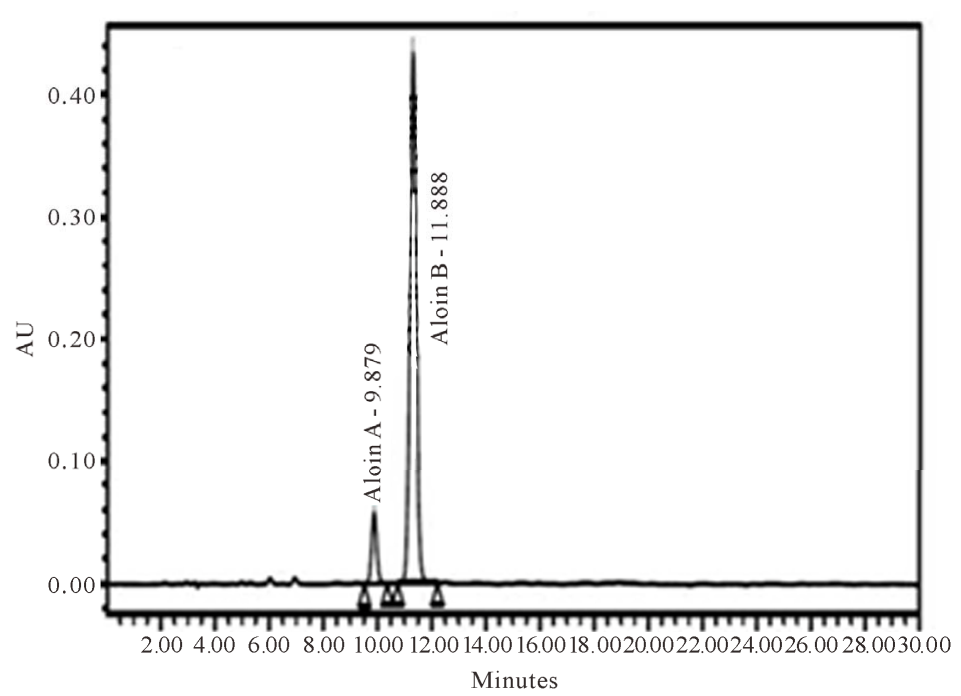

(a)

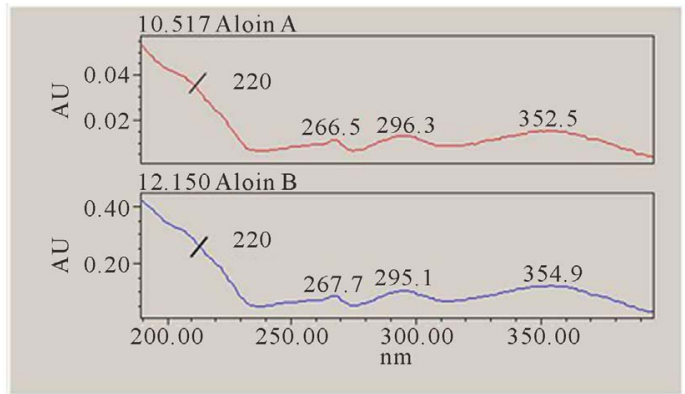

(b)

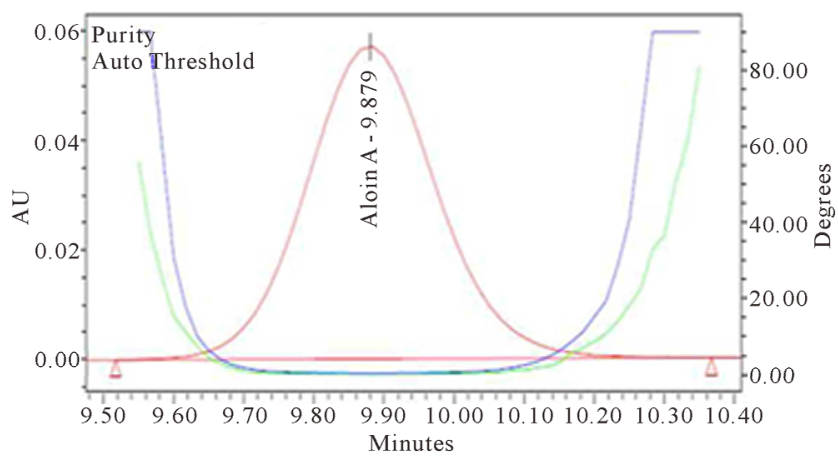

(c)

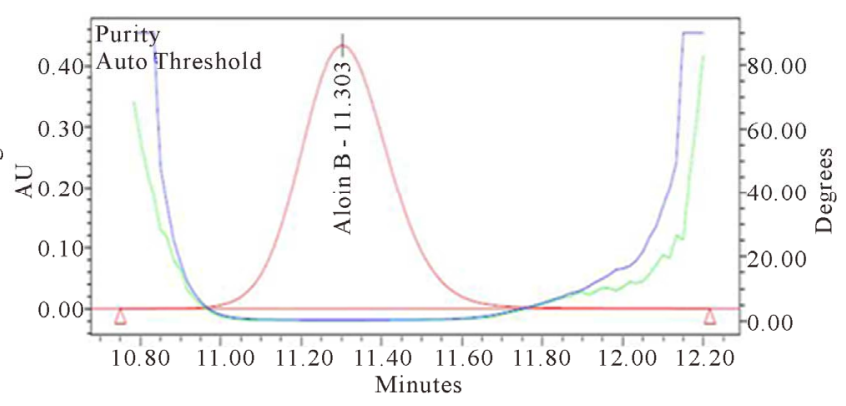

(d)

Figure 2. (a) HPLC chromatogram, (b) spectrum shows the maximum absorbance wavelength of $220 \mathrm{~nm}$, (c) and (d) peak purity plot of Aloin A and Aloin B standards which purity angle less than that of purity threshold.

Table 1. Analysis results for samples at different $\mathbf{p H}$ values (initial sample concentration was $28.5 \mu \mathrm{g} \cdot \mathrm{mL}^{-1}$ ).

\begin{tabular}{ccccc}
\hline Sample $\mathrm{pH}$ & $\begin{array}{c}\text { Added } \\
\left(\mu \mathrm{g} \cdot \mathrm{mL}^{-1}\right)\end{array}$ & $\begin{array}{c}\text { Determined } \\
\left(\mu \mathrm{g} \cdot \mathrm{mL}^{-1}\right)\end{array}$ & $\begin{array}{c}\text { Recovery } \\
(\%)\end{array}$ & $\begin{array}{c}\mathrm{RSD} \\
(\%, \mathrm{n}-3)\end{array}$ \\
\hline \multirow{2}{*}{2.0} & 0 & 28.4 & 99.65 & 2.6 \\
& 10 & 38.3 & 100.78 & 1.5 \\
& 50 & 78.2 & 99.62 & 3.5 \\
4.0 & 0 & 28.5 & 100.00 & 2.4 \\
& 10 & 38.1 & 98.96 & 1.7 \\
& 50 & 78.5 & 100.00 & 1.3 \\
6.0 & 0 & 28.7 & 100.70 & 3.8 \\
& 10 & 38.6 & 100.26 & 2.5 \\
& 50 & 78.2 & 99.62 & 2.3 \\
\hline
\end{tabular}

of 9.9 and 11.9 min respectively and it is tabulated in Table 2. The major peak at $2.4 \mathrm{~min}$ is due to the isolation of aloe emodin. These values are correlated well with the reported results. From the above studies it is observed that the major active components are present in the brown colored Aloe vera plant gels (Figures 4 and 5).
Table 2. The retention time (RT) of Aloe vera extract and reference standard.

\begin{tabular}{|c|c|c|c|}
\hline \multirow{2}{*}{ S. No. } & \multirow{2}{*}{ Peak } & Aloe vera extract & Reference Standard \\
\hline & & \multicolumn{2}{|c|}{$\mathrm{RT}(\min )$} \\
\hline 1 & Aloe-emodin peak & 2.4 & -- \\
\hline 2 & Aloin A peak & 9.5 & 9.4 \\
\hline 3 & Aloin B peak & 11.0 & 10.0 \\
\hline
\end{tabular}

The presence of Aloins A, B and aloe emodin in four different samples were identified (Figure 4). The commercially available products were analyzed using HPLC to identify the active components present in it. Three major peaks were identified for each sample. In some cases one or two components are seen which can be due to the low concentration of the active components (Figure 3). A calibration plot of Aloins A and B were generated using a known authentic sample. From this graph the unknown concentration of Aloins A and B can be measured (Figures 6(a) and (b)). Three concentrations of the calibration standard were spiked into the blank 


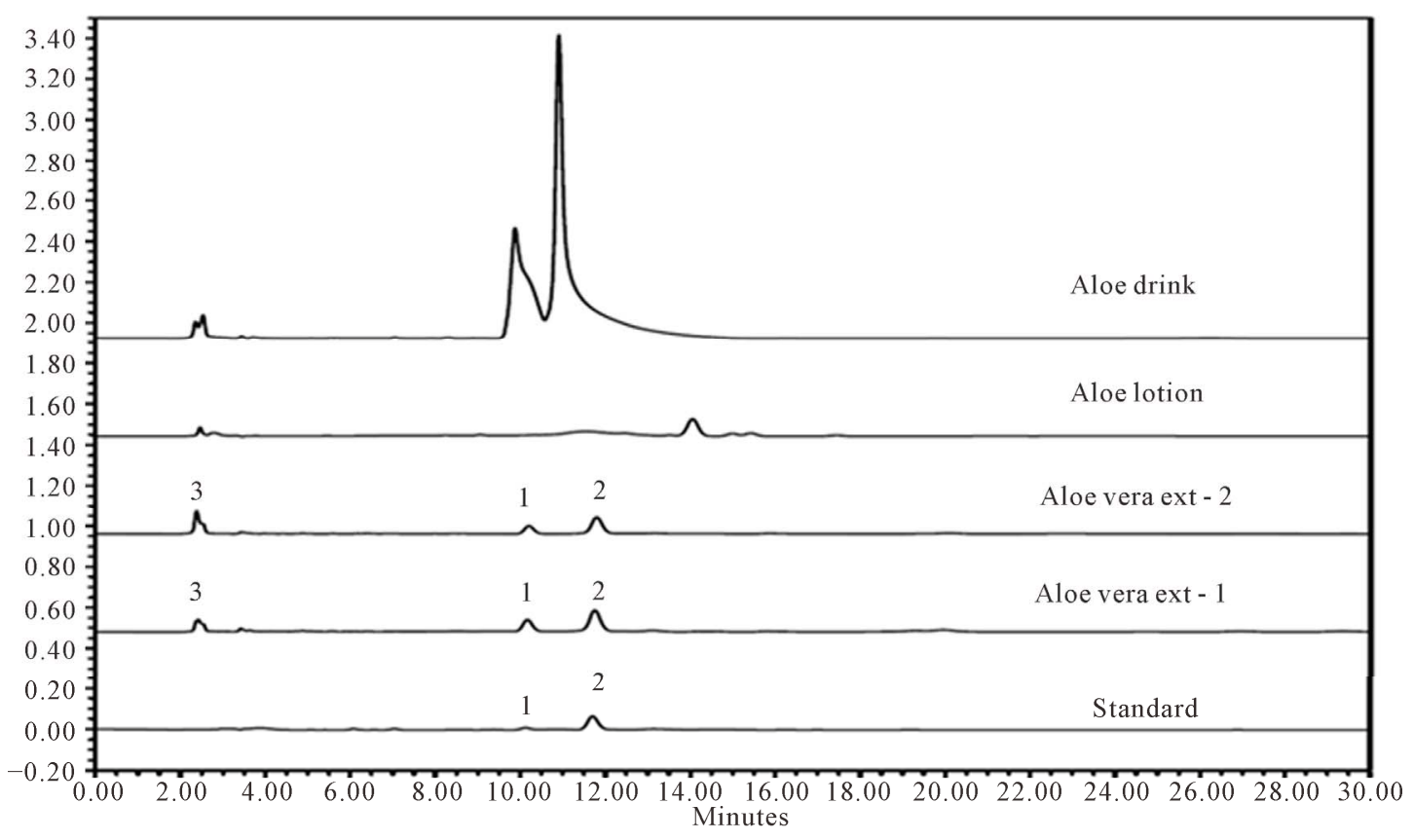

Figure 3. HPLC chromatograms of aloin and aloe-emodin [1. Aloin A; 2. Aloin B; 3. aloe-emodin] in aloe-extract, aloe containing samples and reference standard.

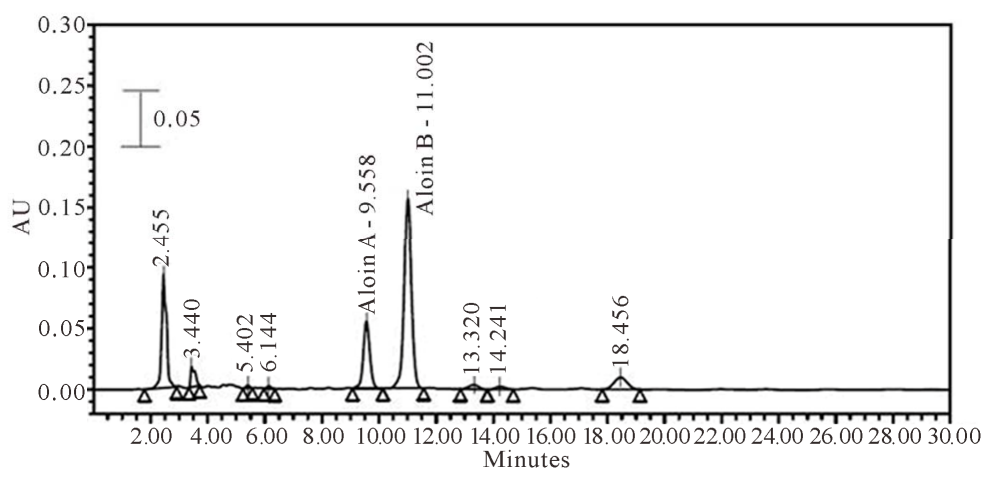

Figure 4. HPLC chromatograms of aloe-extract containing Aloe-emodin, Aloin A and Aloin B.

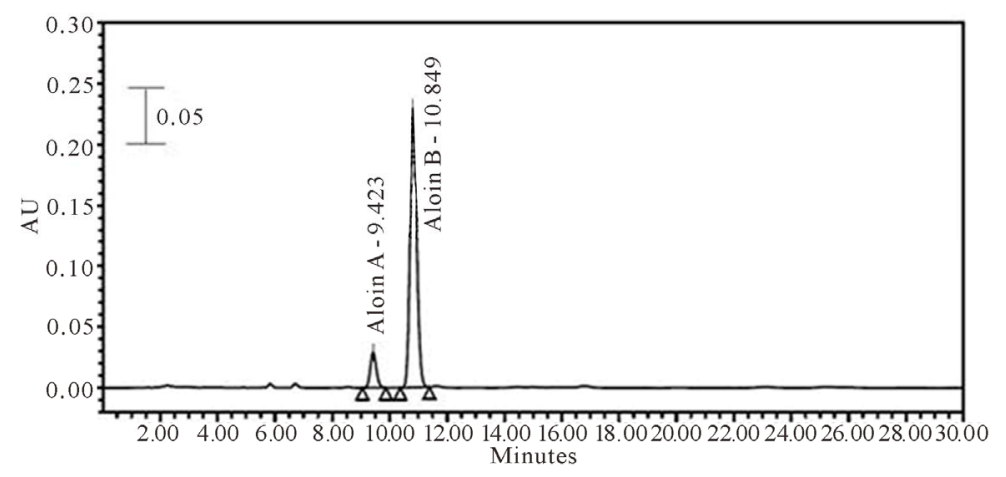

Figure 5. HPLC of reference standard Aloin A and Aloin B.

samples and assayed by HPLC. The recoveries were determined by the percentage of the calculated concentration versus the theoretical concentration (Figure 7). The results indicated that this study established a feasible method for flavonoid detection in commercial formulated products. 


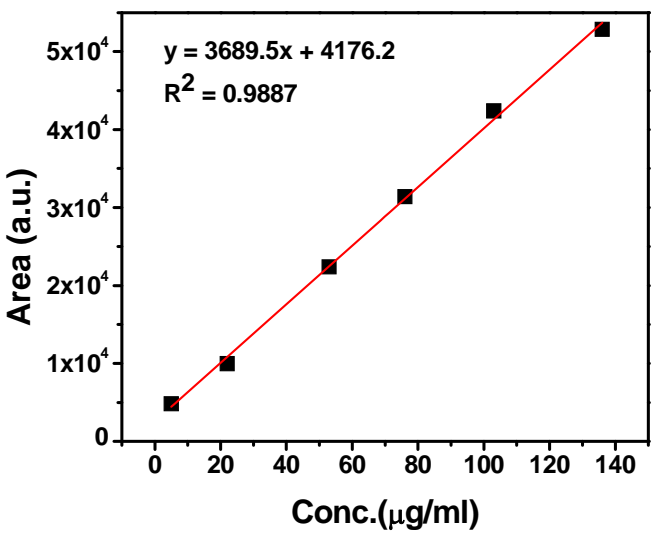

(a)

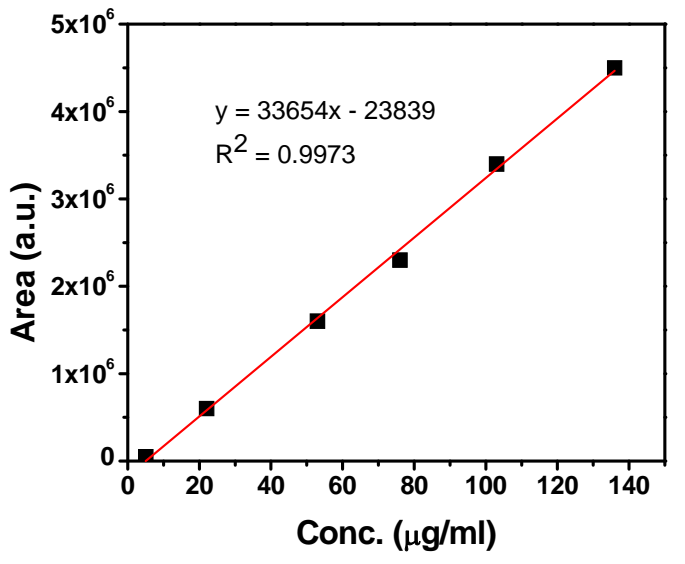

(b)

Figure 6. (a) Linearity graph of Aloin A; (b) Linearity graph of Aloin B.
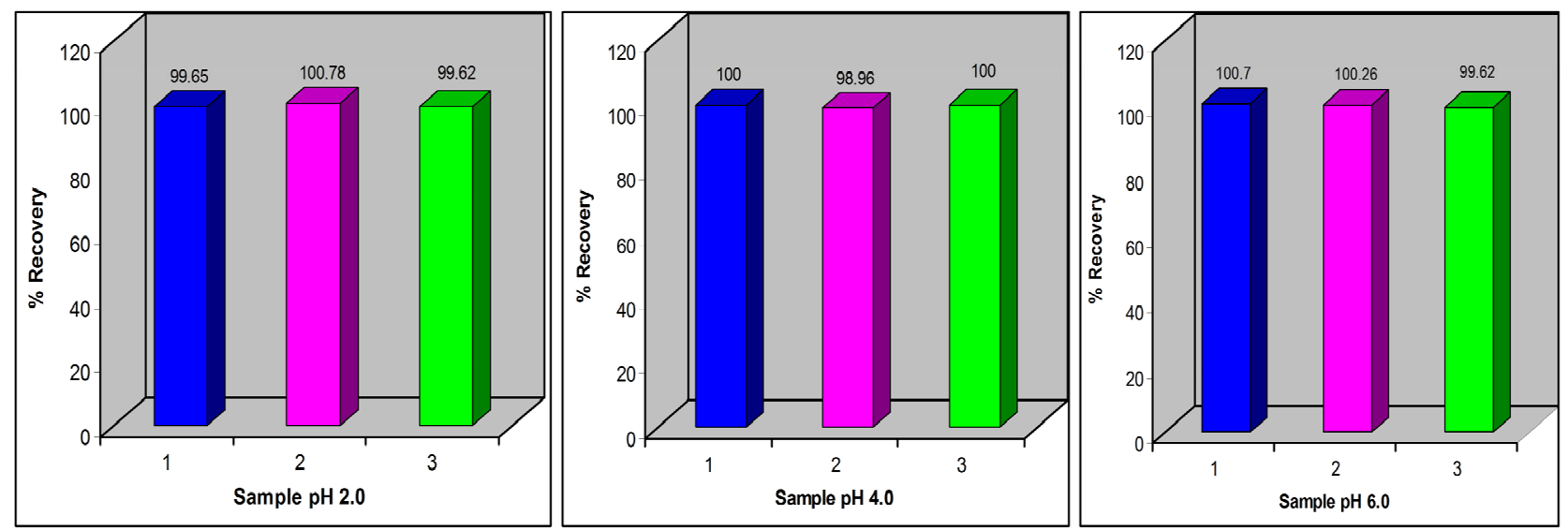

Figure 7. Recovery of samples in percentage, $\mathrm{pH}$ 2.0, 4.0 and 6.0.

\section{Conclusion}

We have developed an analytical method based on HPLC for validation and determination of Aloins A and $\mathrm{B}$ contained in the extract and derived formulations. The proposed method is simple and shows good sensitivity, precision and this method can be extended for the analysis of bioactive compounds present in the commercial formulations to study their adulteration from the product available in the market. In comparison with the previously reported methods, the proposed one had advantages for the scientific validation of aloin content in the commercial products.

\section{REFERENCES}

[1] E. S. Femenia, S. Sanchez, C. Simal and Rossello, "Compositional Features of Polysaccharides from Aloe vera (Aloe barbadensis Miller) Plant Tissues," Carbohydrate Polymers, Vol. 39, No. 2, 1999, pp. 109-117. http://dx.doi.org/10.1016/S0144-8617(98)00163-5

[2] E. Aysan, H. Bektas and F. Ersoz, "A New Approach to
Post-operative Peritoneal Adhesions: Prevention of Peritoneal Trauma by Aloe vera Gel," European Journal of Obstetrics \& Gynecology and Reproductive Biology, Vol. 149, No. 2, 2010, pp. 195-198.

http://dx.doi.org/10.1016/j.ejogrb.2009.11.019

[3] N. Pugh, S. A. Ross, M. A. ElSohly and D. S. Pasco, "Characterization of Aloeride, a New High-MolecularWeight Polysaccharide from Aloe vera with Potent Immunostimulatory Activity," Journal of Agricultural and Food Chemistry, Vol. 49, No. 2, 2001, pp. 1030-1034. http://dx.doi.org/10.1021/jf001036d

[4] J. B. Wang, H. F. Li, C. Jin, Y. Qu and X. H. Xiao, "Development and Validation of a HPLC Method for Quality Control of Rhubarb-Based Medicine: Fast Simultaneous Determination of Five Anthraquinone Derivatives," Journal of Pharmaceutical and Biomedical Analysis, Vol. 47, No. 4-5, 2008, pp. 765-770.

[5] E. L. Duarte, T. R. Oliveira, D. S. Alves, V. Micol and M. T. Lamy, "On the Interaction of the Anthraquinone Barbaloin with Negatively Charged DMPG Bilayers," Langmuir, Vol. 24, No. 8, 2008, pp. 4041-4049. http://dx.doi.org/10.1021/la703896w

[6] M. A. ElSohly, W. Gul and T. P. Murphy, "Analysis of 
the Anthraquinones Aloe-emodin and Aloin by Gas Chromatography/Mass Spectrometry," Journal of Pharmaceutical and Biomedical Analysis, Vol. 4, No. 14, 2004, pp. 1739-1744.

http://dx.doi.org/10.1016/j.intimp.2004.07.005

[7] P. K. Mukherjee, N. Maity, N. K. Nema and B. K. Sarkar, "Bioactive Compounds from Natural Resources against Skin Aging," Phytomedicine, Vol. 19, No. 1, 2011, pp. 64-73. http://dx.doi.org/10.1016/j.phymed.2011.10.003

[8] C. V. Di Anibal, I. Ruisánchez, M. Fernández, R. Forteza, V. Cerda and M. P. Callao, "Standardization of UVVisible Data in a Food Adulteration Classification Problem," Food Chemistry, Vol. 134, No. 4, 2012, pp. 23262331. http://dx.doi.org/10.1016/j.foodchem.2012.03.100

[9] R. Mandrioli, L. Mercolini, A. Ferranti, S. Fanali and M. A. Raggi, "Determination of Aloe Emodin in Aloe vera Extracts and Commercial Formulations by HPLC with Tandem UV Absorption and Fluorescence Detection," Food Chemistry, Vol. 126, No. 1, 2011, pp. 387-393. http://dx.doi.org/10.1016/j.foodchem.2010.10.112

[10] A. Shotipruk, J. Kiatsongserm, P. Pavasant, M. Goto and M. Sasaki, "Pressurized Hot Water Extraction of Anthraquinones from the Roots of Morindacitrifolia," Biotechnology Progress, Vol. 20, No. 6, 2004, pp. 1872-1875. http://dx.doi.org/10.1021/bp049779x

[11] C. X. Lu, H. X. Wang, W. P. Lv, C. Y. Ma, P. Xu, J. Zhu, J. Xie, B. Liu and Q. L. Zhou, "Ionic Liquid-Based Ultrasonic/Microwave-Assisted Extraction Combined with HPLC for the Determination of Anthraquinones in Rhubarb," Chromatographia, Vol. 74, No. 1-2, 2011, pp. 139-144. http://dx.doi.org/10.1007/s10337-011-2023-5
[12] S. Genovese, F. Tammaro, L. Menghini, G. Carlucci, F. Epifano and M. Locatelli, "Comparison of Three Different Extraction Methods and HPLC Determination of the Anthraquinones Aloe-Emodin, Emodin, Rheine, Chrysophanol and Physcione in the Bark of Rhamnusalpinus L. (Rhamnaceae)," Phytochemical Analysis, Vol. 21, No. 3, 2010, pp. 261-267. http://dx.doi.org/10.1002/pca.1195

[13] R. Gautam, A. Srivastava and S. M. Jachak, "Simultaneous Determination of Naphthalene and Anthraquinone Derivatives in Rumexnepalensisspreng Roots by HPLC: Comparison of Different Extraction Methods and Validation," Phytochemical Analysis, Vol. 22, No. 2, 2011, pp. 153-157. http://dx.doi.org/10.1002/pca.1261

[14] K. E. Gutowski, G. A. Broker, H. D. Willauer, J. G. Huddleston, R. P. Swatloski, J. D. Holbrey and R. D. Rogers, "Controlling the Aqueous Miscibility of Ionic Liquids: Aqueous Biphasic Systems of Water-Miscible Ionic Liquids and Water Structuring Salts for Recycle, Metathesis and Separations," Journal of the American Chemical Society, Vol. 125, No. 22, 2003, pp. 6632-6633. http://dx.doi.org/10.1021/ja0351802

[15] Z. J. Tan, F. F. Li and J. M. Xing, "Separation and Purification of Aloe Anthraquinones Using PEG/Salt Aqueous Two-Phase System," Separation Science and Technology, Vol. 46, No. 9, 2011, pp. 1503-1510. http://dx.doi.org/10.1080/01496395.2011.563766

[16] Z. J. Tan, F. F. Li and X. L. Xu, "Isolation and Purification of Aloe Anthraquinones Based on an Ionic Liquid/Salt Aqueous Two-Phase System," Separation Science and Technology, Vol. 98, 2011, pp. 150-157. 